\title{
Presencia de Paulo Freire: Piezas de vida
}

\section{Presence of Paulo Freire: Pieces of life}

José Beltrán Llavador

Universitat de València Jose.Beltran@uv.es

ORCID ID: https: / / orcid.org/0000-0003-1065-3032

Francesc J. Hernàndez

Universitat de València

Francesc.J.Hernàndez@uv.es

ORCID ID: https: / / orcid.org/0000-0001-5229-2998

Rosa Isusi-Fagoaga ${ }^{1}$

Universitat de València

Rosa.Isusi@uv.es

ORCID ID: https:/ / orcid.org/0000-0003-3727-3865

"La Educación no cambia el mundo, cambia a las personas que van a cambiar el mundo". Paulo Freire

Hace veinticinco años, en 1995, Paulo Freire impartió una Conferencia en la sede de la Universidad Internacional Menéndez Pelayo (UIMP) de la ciudad de València. Fue invitado por la Conselleria de Educación y por la Mesa de los Agentes Sociales para la Formación Permanente de Adultos a impartir la conferencia inaugural en unas jornadas denominadas La importancia estratégica de la Formación de las Personas Adultas. Estas jornadas se impartieron consecutivamente en las ciudades de Valencia, Castellón y Alicante con motivo de la aprobación de la Ley Valenciana de Formación de Personas Adultas. La presencia de Paulo Freire en Valencia constituyó un acontecimiento histórico que merece ser recordado y compartido por nuestra comunidad educativa y también internacionalmente. Por otra parte, en 2021 se cumple el centenario del nacimiento Paulo Freire [1921-1997).

$1 \quad$ Los tres han coordinado el presente número monográfico sobre Paulo Freire. 
Fig. 1. Paulo Freire en el seminario organizado en València, 30 de marzo de 1995. Fotografía de Carmen Montañana.

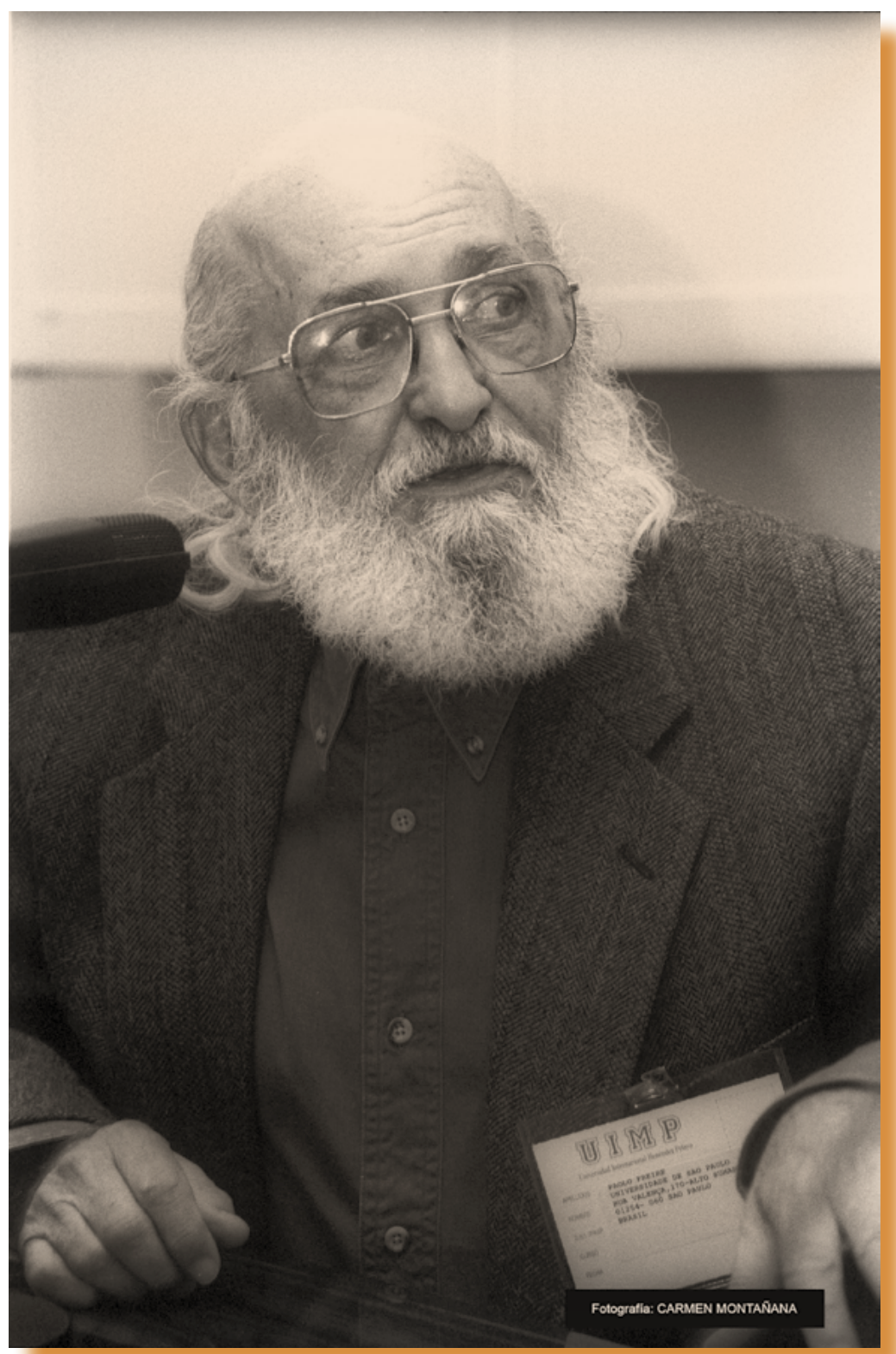

El brasileño Paulo Freire ha sido uno de los mayores y más significativos pedagogos del siglo $X X$ cuyas ideas han llegado a influir en los procesos de democratización en todo el mundo. Sus principales aportaciones a la pedagogía sientan sus bases en el método de que todo proceso educativo debe partir de la realidad que rodea a las personas, de hecho defendió su tesis doctoral con el título ya significativo La educación y la realidad brasileña en 1959 en la Universidad de Recife, su localidad natal. También inició un nuevo camino en la relación entre el profesorado y estudiantes con su principio del diálogo que tanto ha influido posteriormente.

La educación para Freire fue el medio para mejorar su sociedad y el mundo. En ese sentido, realizó grandes campañas de alfabetización en su país. Tras el golpe militar en el Brasil de 1964, su actividad educativa fue calificada de subversiva por lo que tuvo que exiliarse y marchó a Chile. 
Alli participó con el gobierno en varios programas educativos para personas adultas y escribió su determinante libro Pedagogía del oprimido(1968). Fundamentalmente, la pedagogía del oprimido es una pedagogía humanista y liberadora que tendrá, pues, dos momentos distintos e interrelacionados. El primero, en el cual los oprimidos van desvelando el mundo de la opresión y se van comprometiendo, en la praxis, con su transformación, y, el segundo, en que, una vez transformada la realidad opresora, esta pedagogía deja de ser del oprimido y pasa a ser la pedagogía de los sujetos en proceso de permanente liberación. Freire escribió este libro conociendo muy bien desde niño la realidad del nordeste brasileño, en el que en un pasado muy cercano a él se había vivido en esclavitud y en su presente las clases rurales vivían en relaciones laborales de opresión, marginadas del proceso social, político y económico y sin participación alguna en las decisiones importantes para el país. Es por ello que en aquel entonces Freire impulsa a sus coetáneos a romper su pasividad y silencio, a reconocer la fuerza de su unidad transformadora y a que adquieran la capacidad crítica para relacionarse con la sociedad yque se liberen de sus ataduras, única posibilidad de cambio de la sociedad.

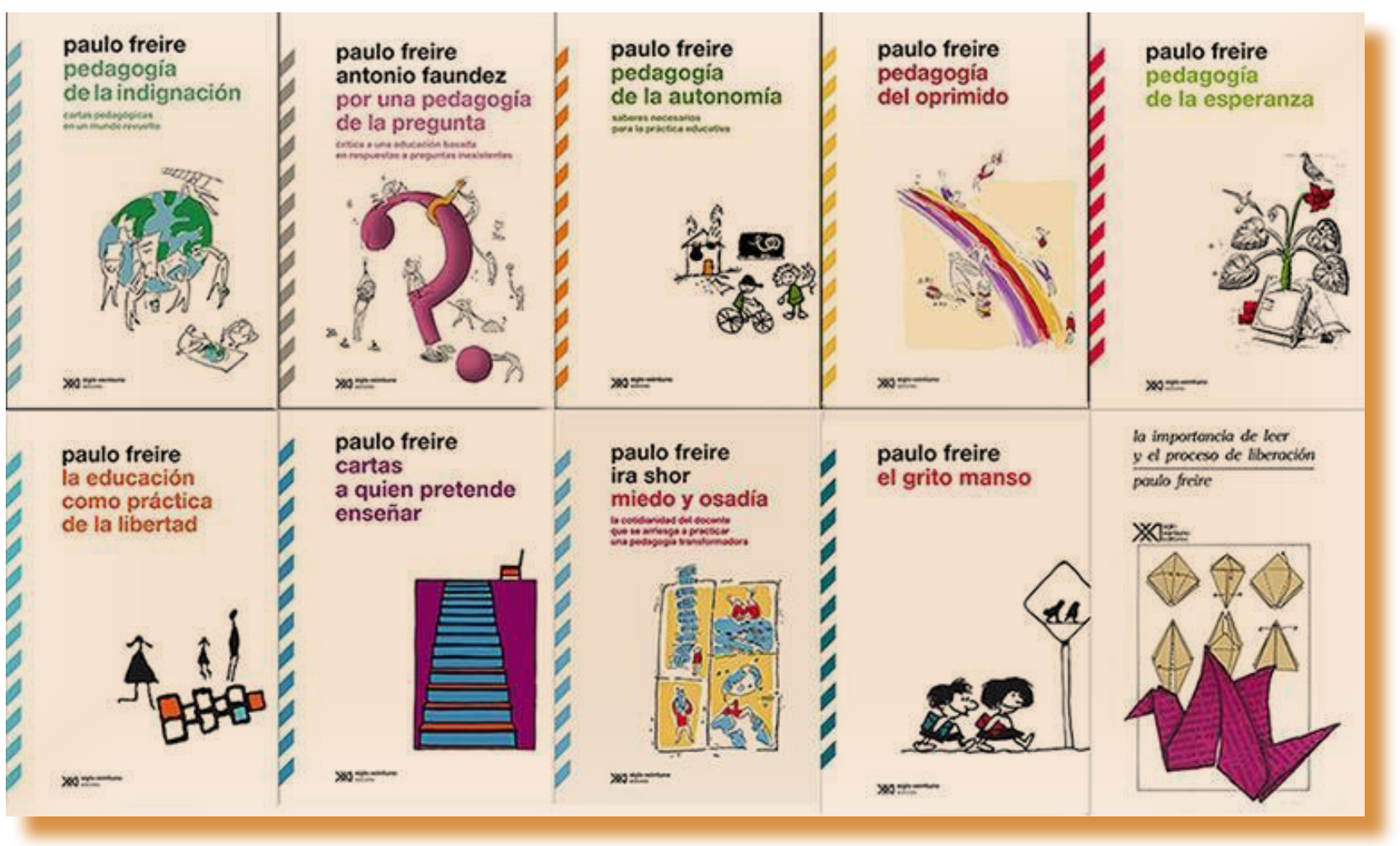

Fig. 2. Selección de diez libros de Paulo Freire

Las ideas transformadoras de la sociedad a través de la educación de Paulo Freire se insertan en las nuevas perspectivas revolucionarias que existían en América Latina en los años 1960-70. Es por ello que tuvo que volver a exiliarse y finalmente se estableció en Ginebra [Suiza] donde trabajó en los programas educativos del Consejo Mundial de las Iglesias. Después de dieciséis años de exilio, en 1980 volvió a Brasil, impartiendo docencia en la Universidade Estadual de Campinas y en la Pontifícia Universidade Católica de São Paulo, ciudad esta última de la que fue Secretário de Educação. En 1986, recibió el premio internacional "Paz y Educación" de la UNESCO. Fue 
investido doctor honoris causa por una veintena de universidades de todo el mundo. A lo largo de su trayectoria publicó casi medio centenar de escritos que han tenido una enorme influencia no solo en el ámbito educativo sino también social, económico y político.

La revista Creativity and Educational Innovation Review [CEIR] ha querido conmemorar con un número monográfico la figura de este pensador y educador universal que fue Paulo Freire a partir de las dos efemérides mencionadas. Este cuarto número de la revista se puede calificar de extraordinario por diferentes motivos. Este monográfico contiene textos que constituyen un ejercicio de memoria histórica reciente y suponen auténticas piezas de vida, a base de reflexiones, testimonios, imágenes y documentos. Además, este ejemplar contiene una serie de aportaciones especiales en forma de saludos para la ocasión que se suman al homenaje a Paulo Freire. Todos los textos y aportaciones están centradas en una obra y filosofía pedagógica que sigue vigente porque sigue inspirando a investigadores y pedagogos y contribuyen a la reinvención de su pensamiento, como pedía el propio Paulo Freire en los últimos años de su vida. También en la sección de reseñas se han seleccionado dos libros relacionados con la necesidad de mejorar nuestra sociedad a través del conocimiento desde diferentes enfoques.

En la primera sección "Dialogando con" con la que se da comienzo a este monográfico sobre Paulo Freire -y a modo de obertura - se ofrece una entrevista comentada que Laura Peris realiza a Joan Romero, Conseller d'Educació y promotor de la Ley Valenciana de Formación de Personas Adultas en 1995, año en que Freire estuvo en Valencia. En este texto titulado Dialogando con Joan Romero González sobre Paulo Freire: El valor transformador de la educación, la formación permanente y a lo largo de la vida, se rememoran no solo las circunstancias que hicieron posible la presencia de Paulo Freire en Valencia, sino que entrelaza ese recuerdo con cuestiones de relevancia en la agenda educativa y social contemporánea.

A continuación, la sección de textos invitados empieza con el profesor Carlos Alberto Torres,del cual se presenta su prefacio al libro Educación y neoliberalismo. Ensayos de oposición. En este prefacio evoca de manera emotiva la última conversación telefónica que mantuvo con Paulo Freire poco antes de fallecer. Freire fue y sigue siendo una figura central -maestro y amigopara Carlos Alberto Torres, que le ha dedicado buena parte de su extensa producción académica y que se ha convertido en gran impulsor de su obra a través de la dirección del Instituto Paulo Freire en la Universidad de California, sede de Los Ángeles [UCLA]en Estados Unidos de América.

Le sigue una recopilación de textos denominados Palabras para Paulo Freire,en la que se reúnen algunos saludos internacionales y locales como tributo al educador universal que fue Freire. Son un conjunto de 17 textos de colegas expertos del ámbito académico, docente e investigador procedentes de Brasil, Portugal, Japón, Estados Unidos y España, que han respondido amablemente a nuestra invitación. El hilo conductor de todos ellos es el reconocimiento a una vida y una obra que siguen siendo inspiradoras, y en algunos casos, ofrecen el testimonio personal de quienes tuvieron el privilegio de conocer al educador y disfrutar de su magisterio.

Cierra esta sección un texto de Agustí Pascual Cabo en el que presenta unas consideraciones sobre el Seminario Internacional en el que Paulo Freire pronunció su conferencia en tierras valencianas 
bajo el título Notes sobre el Seminari Internacional: La importància Estratègica de la Formació de les Persones Adultes, organitzat per la UIMP a Castelló. En realidad su texto es algo más que una suma de notas: es la evocación de una rica conversación que el autor mantuvo con Basil Bernstein en Castellón, en el mismo Seminario Internacional que se conmemora con este monográfico. Esta conversación le sirve de hilo conductor para vincular las teorías sobre el discurso pedagógico del sociólogo y lingüista británico con el currículum de educación de personas adultas, una reflexión que Agustí Pascual, profesor del centro específico a distancia de la Comunidad Valencia y de la Universitat de València, desarrollaría de manera muy amplia y fundamentada en su tesis doctoral.

La sección de artículos da comienzo con un estudio realizado por José Antonio Veiga Gómez, director del seminario internacional en el que Paulo Freire pronunció la conferencia inaugural, y asesor del entonces Conseller d’Educació, que impulsó la Ley Valenciana de Formación de Personas Adultas. En este artículo, Veiga Gómez recrea y analiza el contexto social en el que se desarrolló el excepcional seminario, que celebró y dio una amplia proyección a una ley educativa progresista que supuso un impulso institucional sin precedentes para la educación de personas adultas, un precedente notable de lo que después pasaría a ser una parte central de las políticas europeas de aprendizaje permanente y educación a lo largo de la vida. El artículo no es solo un reportaje científico, sino un testimonio biográfico directo por parte de un actor y testigo privilegiado de los acontecimientos que tuvieron lugar en 1995. Como ilustración de todo ello, el artículo incluye algunas fotografías inéditas de Paulo Freire y de quienes le acompañaron en el programa del seminario de la UIMP.

Le sigue un trabajo realizado por cuatro académicas procedentes dela Universidade Federal de Paraíba, situada al nordeste de Brasil. Estas investigadoras expertas en la perspectiva educativa y en la obra de Freire presentan un texto que pone el acento en la actualidad de sus reflexiones, como refleja el título de su propuesta Perspectiva contemporânea das ideias de Paulo Freire. Las autoras son las profesoras Claudia Suely Ferreira Gomes, Maria das Graças Gonçalves Vieira Guerra, Emilia Maria da Trindade Prestes y Adriana Valeria Santos Diniz. El título de su artículo describe muy bien la intención del mismo, que actualiza el pensamiento de Freire en un mundo intercultural de complejidad creciente. Las autoras fundamentan, con argumentos teóricos, la presencia y la vigencia actual de la obra de Paulo Freire.

Da Pedagogia do Oprimido à Pedagogia do Reconhecimento: Um diálogo entre o pensamento de Paulo Freire e Axel Honneth es el título del tercer artículo, a cargo de Francisco das Chagas Galvão de Limade la Universidade Federal da Paraíba en Brasil y José Beltrán, profesor en el Departamento de Sociología y Antropología Social de la Universidad de València. Aquí, ambos autores plantean la hipótesis de que es posible reinventar y actualizar el pensamiento de Paulo Freire desde la perspectiva que propone Axel Honneth. Lo que sugiere este trabajo es la reinterpretación de la noción de "pedagogía del oprimido" del educador brasileño como una "pedagogía del reconocimiento", a partir de la teoría del reconocimiento del pensador alemán.

Le sigue un artículo, a cargo de Francesc J. Hernàndez, titulado Freirismo, desigualdad social y educativa, en el que no se lleva a cabo tanto una reflexión sobre Freire, sino más bien a 
partir de Freire. El autor, profesor en el Departamento de Sociología y Antropología Social de la Universitat de València y director del Instituto de Creatividad e Innovaciones Educativas, plantea una pregunta relevante que nos da la clave del rechazo de Bolsonaro, actual dirigente político de Brasil, a la obra de Freire. Y la respuesta es radical e inapelable: Bolsonaro no soporta a Paulo Freire, y por eso lo censura, porque desde su libro fundacional Pedagogía del Oprimido, Freire desarrolla una obra de denuncia y desenmascaramiento de las desigualdades sociales, reproducidas, aumentadas y legitimadas por gobiernos conservadores y autoritarios. Según el autor mientras haya desigualdades educativas, la obra de Paulo Freire será una fuente de inspiración para combatirlas, gozando de plena actualidad, y además seguirá siendo una obra necesariamente incómoda para quienes pretendan mantener el privilegio de clase.

Finaliza la sección de artículos un texto de José Beltrán que adapta y actualiza para la ocasión el trabajo La vida de las palabras. Un diálogo posible entre Paulo Freire y Martin Heidegger, que tuvo ocasión de presentar en un foro internacional dedicado a Paulo Freire en la Universidade Nove de Julho, en Sao Paulo [Brasil). Se trata de un debate dialéctico entre el pensador brasileño y el filósofo alemán. Y una excusa para recordar la importancia de "apalabrar el mundo" para renovarlo con nuevos significados que nos ayuden a su preservación y mejora.

Cierra el número de la revista de este año la sección de reseñas con dos libros publicados en este año y el anterior. Se trata de dos libros relacionados con la educación con diferentes particularidades cada uno de ellos. Por una parte, un libro centrado en uno de los temas que ha cobrado mayor protagonismo en los últimos tiempos dentro del ámbito académico, como es la transferencia de conocimiento. Por otra, otro libro de gran interés que ofrece un material didáctico con contenido de sociología de la educación en un original formato de cómic.

En el primer caso, la investigadora científica del CSIC adscrita al centro mixto INGENIO en la Universidad Politécnica de Valencia, Adela García-Aracil, experta en innovación, transferencia y economía de la educación realiza un análisis comentado sobre el libro editado por el catedrático de la Universidad de Santiago de Compostela Miguel Ángel Santos Rego. Este libro,que reúne capítulos elaborados por más de una veintena de profesores universitarios con una amplia y sólida trayectoria académica con diferentes perspectivas y aproximaciones al complejo y controvertido tema de la transferencia de conocimiento, profundizando en el ámbito educativo, tema que había recibido escasa atención por parte de los investigadores hasta fechas recientes. El libro ha sido publicado el presente año en una editorial de prestigio, como es Narcea.

En el segundo caso, el profesor del Departamento de Sociología y Antropología Social de la Universidad de Valencia, Jordi Giner Monfort realiza un comentario sobre el trabajo académico de la estudiante de Grado en Maestro/a en la Facultad de Magisterio de Anna Ramon Albert. Este trabajo destaca por su gran creatividad al incorporar el formato de cómic a un contenido basado en una asignatura universitaria de sociología de la educación y además añade el aliciente de estar basado en hechos reales. Constituye no solo un gran ejemplo de elaboración de materiales didácticos adaptados al mundo actual y motivadores para el estudiantado universitario, sino también de difusión del conocimiento académico, en este caso mediante la publicación en una editorial de excelencia como es Tirant lo Blanch. El trabajo realizado por Anna Ramon y tutorizado 
por el profesor José Beltrán muestra un buen modelo a seguir no solo por otros estudiantes sino también por los profesionales de la docencia universitaria.

Además de todos estos contenidos, este número cuenta con tres extensiones en formato monografía que lo complementan. Se trata de tres publicaciones que salen a la luz en la colección Monografies \& Aproximacions, con los números 23, 28 y 29 en la página web del Institut de Creativitat i Innovacions Educatives ${ }^{2}$.

La primera de ellas es un estudio reciente de la socióloga María Checa Vilar, titulado Gracias a la educación a lo largo de la vida: Las contribuciones sociales del Programa Nau Gran de la Universitat de València [https://www.uv.es/mia1/MiA23.pdf). En este trabajo, la autora destaca los beneficios de este Programa Universitario para Mayores desde su puesta en marcha en 1999. La educación de personas adultas y la educación a lo largo de la vida han ido ganando centralidad en las políticas educativas europeas, y en la actualidad suponen un auténtico giro educativo en el horizonte de una educación para la ciudadanía mundial.

La segunda, con el número 28,es el dossier completo - recuperado para la ocasión- de los materiales de lectura y trabajo que se repartieron en el Seminario Internacional de la UIMP con una introducción del director del mencionado seminario José Antonio Veiga Gómez.

La tercera con el número 29, es la transcripción del contenido de la conferencia en castellano y en portugués. Además, en este monográfico se recupera y se hace pública, por primera vez después de 25 años, la grabación audiovisual original de la conferencia que impartió el pedagogo brasileño con el título La naturaleza política de la Formación de Personas Adultas [https:// youtu.be/unjZ3/zpLVs ]. No sólo se presenta este documento audiovisual, que tiene una enorme importancia desde el punto de vista histórico, cultural y patrimonial. Puesto que la ocasión que aquí se rememora es excepcional, también se ha reunido en este monográfico una memoria gráfica de la conferencia de Paulo Freire, un reportaje fotográfico, cuya autora es Carmen Montañana. Son fotografías inéditas que recrean algunos momentos y escenas del Seminario, en los que Paulo Freire ocupa un primer plano o conversa con algunos de los ponentes y participantes. Las fotografías, de un enorme valor humano, son tan expresivas como elocuentes: hablan por sí mismas.

Paulo Freire sonreiría al conocer esta noticia y sin duda le serviría como ejemplo de una de sus expresiones más célebres que introdujo en Pedagogía de la esperanza (1992]:“inédito viable”. Lo que permanecía sin editar se ha materializado, se ha hecho posible. Sin duda, esta es una aportación relevante para el ámbito educativo y para el mundo de la cultura en general.

El título de esta presentación expresa la intención de este número monográfico: dejar constancia, a través de un conjunto de piezas de vida, de la presencia de Paulo Freire, de la vigencia y actualidad de su pensamiento, y de su valioso legado para las generaciones venideras. Estas páginas nos abren paso a algunas calles de la Historia por las que pasear como lectores y ciudadanos, en este caso, con el privilegio de tener como compañero de viaje a Paulo Freire. Estas páginas no

2 https://www.uv.es/uvweb/instituto-creatividad-innovaciones-educativas/es/publicaciones 
solo pueden servir para reconocer la sabiduría de Paulo Freire, sino que pueden inspirarnos para reinventar su obra, y que esta siga guiándonos en la búsqueda incesante de lo inédito viable: una utopía realizable para reescribir y mejorar la sociedad, aprendiendo a pronunciar el mundo y comprometiéndonos con su suerte y renovación. 